\title{
Peri-Implant Tissue Microbiology: A Review
}

\author{
Arife Sabancı ${ }^{1}$ and Abubekir Eltas ${ }^{2 *}$ \\ ${ }^{1}$ Department of Periodontology, Inonu University, Turkey \\ ${ }^{2}$ Department of Periodontology, University of Health Sciences, Turkey
}

Submission: October 22, 2018; Published: November 02, 2018

*Corresponding author: Abubekir Eltas, Department of Periodontology, University of Health Sciences, Turkey, Tel: +902164189616; Fax: +902164189620; Email: aeltas@yahoo.com

\begin{abstract}
Implant therapy is an effective and effective treatment option for removing missing teeth in total or partial edentulous patients. In many studies, there is a high success rate of $92.8 \%$ to $97.1 \%$ in the long-term outcomes of 10 years of implant treatment in the general population. Biological processes leading to implant failure can be slow and gradual. Periodontal and peri-implant diseases are microorganism-related infections. As with periodontal disease, microbial dental plaque also causes the initiation and spread of an inflammatory and immunological tissue response in peri-implant diseases. Therefore, the host response to microorganisms, as it is in the natural teeth, is foreground. Therefore, the use of microbiological parameters plays an important role both in the examination of microbial growth and in routine diagnosis and follow-up. It has been reported that periodontal pathogens become detectable around dental implants, which begin to function in the oral environment, within a month. It is also known that pathogenic bacteria causing destructive periodontal disease to affect dental implants. This is to provide information about microbial factors and peri-implant tissue microbiology in the intended dental implants.
\end{abstract}

Keywords: Peri-implant; Microbiology

Abbreviations: PICF: Peri-Implant Crevicular Fluid; GCF: Gingival Crevicular Fluid

\section{Introduction}

Dental implants are devices made of materials compatible with the tissue, which are placed on the alveolar bone or onto the mucosa, where the prosthetic superstructure is made to restore the function and aesthetics of the missing teeth [1]. Dental implants have been successfully applied for many years to provide the function as a permanent tooth in partial toothless or completely toothless patients [2]. Dental implants, which have become an important alternative treatment instead of lost teeth, are known to be more satisfying and superior in terms of aesthetics, comfort and function compared to traditional prostheses [3].

\section{Peri-implant Tissues and Peri-implant Diseases}

The soft tissues surrounding the implant are called periimplant mucosa while the soft tissues surrounding tooth are called gum. Although there are similarities between these tissues, there are histologically distinct differences [4]. The soft tissues around the implant consist of keratinized and non-keratinized epithelium, similar to the periodontal tissues around the natural tooth. Unlike the natural tooth, there is no periodontal ligament between the implant and the surrounding bone, and the implantbone contact is directly supplied, not by the fibers. Because the dental implants are in direct connection with the bone, the forces applied cannot be compensated. In addition, the peri-implant tissues are devoid of mechanoreceptors in the periodontal region that senses the sense of touch [5].
Pathological changes in the tissues around the implants are called peri-implant diseases. If these inflammatory changes are limited only in the soft tissues, they are called the peri-implant mucositis and they are called peri-implantitis if they are spread to the alveolar bone under the soft tissue [6]. In a systematic review published by Derks et al. [7] in 2015, the prevalence of periimplant mucositis was reported to be between $19 \%$ and $65 \%$, and the prevalence of peri-implantitis was $1 \%$ to $47 \%$ [7]. Clinically typical symptoms of peri-implant infections are edema, redness and bleeding in the soft tissues in the peri-implant mucositis. In peri-implantitis, clinical findings such as an increase in probing depth and detection of radiographic bone loss are added to these clinical symptoms. These symptoms are as in periodontal disease [8]. The etiology of peri-implant diseases and the etiology of periodontal diseases are similar. However, the fact that there is no real fibrous connective tissue attachment around the implants as it is in the teeth makes the tissues around the implant more sensitive to microbial attack. Bacterial infection has a very important role in the success of dental implants. In clinical and animal studies, bacterial plaque accumulation around the implant caused inflammatory reaction in peri-implant tissues [9].

\section{Microbial Factors}

The most important factor in the formation of periodontal disease is pathogenic microorganisms in microbial dental plaque 
[10-12]. It has been reported that researchers conducted various microbiological studies to identify microorganisms that cause disruptive periodontal disease [13]. It has been emphasized that these microorganism complexes can start and maintain the disease in an easily affected host. Studies have shown that most of the pathogenic microorganisms causing periodontal disease are Gram (-) anaerobic rod, Gram (-) facultative rod and Gram (+) facultative and anaerobic cocci and rods [12,14-16].

To date, in clinical, laboratory and experimental studies showing a strong relationship between periodontal disease and microbial dental plaque, microorganisms such as Aggregatibacter actinomycetemcomitans, Porphyromonas gingivalis, Tannerella forsythensis, Fusobacterium nucleatum, Camphylobacter rectus,
Prevotella intermedia, Prevotella nigrescens, Treponema denticola, Eubacterium nodatum, Peptostreptococcus micros, Eikenella corrodens, and some of the spirochetes and Capnocytophaga species have been reported as periodontal pathogens $[13,17,18]$.

Socransky [19] presented a classification according to the structural characteristics of microorganisms found in the plate and found in different studies until today as cocci, rod, spirochetes and mycoplasmas of Gram (-), Gram (+); facultative anaerobe, mandatory anaerobe; cocci, rod, spirochet and mycoplasmas, and classified microbial species under different color groups (Figure 1). According to this grouping, significant relationship has been found between important clinical findings of periodontal disease and especially red and orange complex species [19].

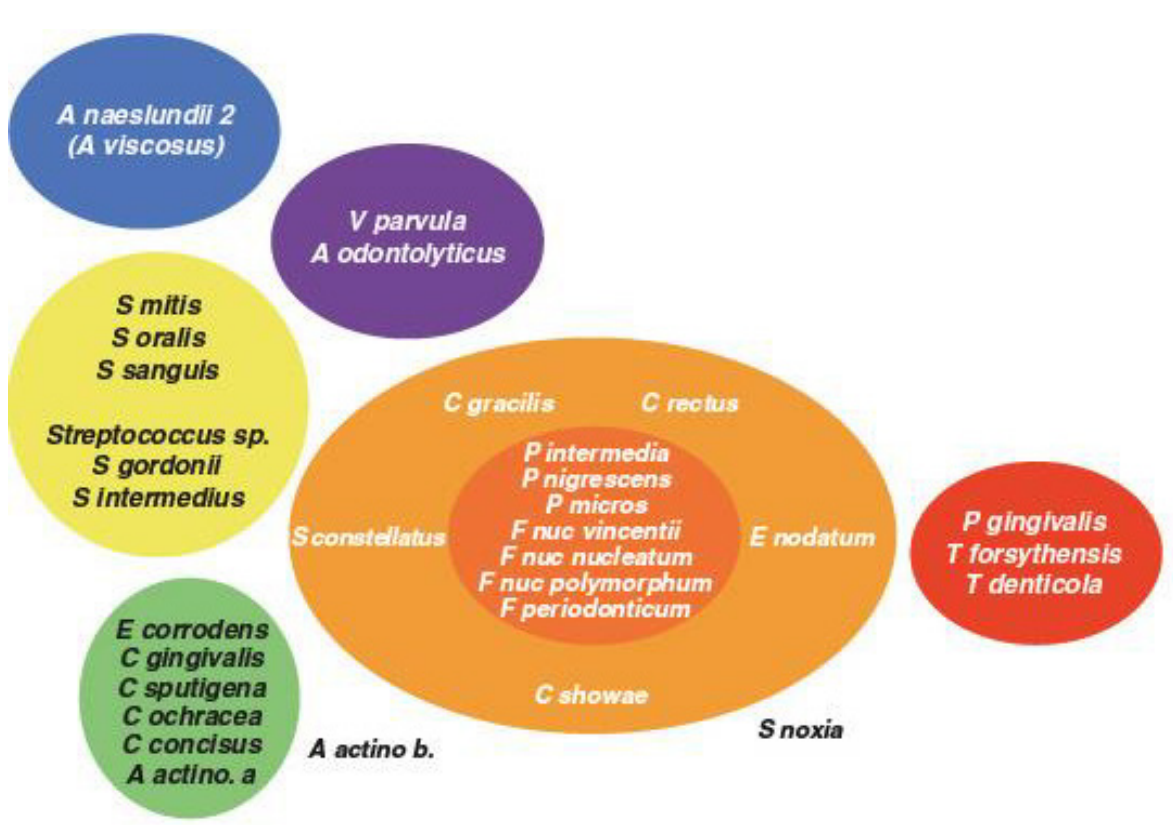

Figure 1: Bacteria types in microbial complexes.

As a result of many years of studies Aggregatibacter actinomycetemcomitans (A.a), Porpyhromonas gingivalis (P.g), Tannerella forsythensis (T.f) have been reported to have a strong relationship with periodontal disease $[17,19]$. In the 1996 Periodontology Workshop, it was decided that these species are periodontal pathogens, and that other species such as F.nucleatum, C.rectus, P.intermedia, P. nigrescens, E.nodatum, P.micros, S.sputigena and some of the spirochetes have been reported to cause periodontal disease [13].

\section{Microbial Accumulation in Implants}

Studies have shown that microbial dental plaque formation on the implant is similar to natural teeth. In peri-implant diseases, as in periodontal diseases, microbial dental plaque causes the initiation and spread of the inflammatory and immunological tissue response. The subsequent amount of peri-implant tissue destruction is closely related to the severity of the inflammatory response. Therefore, as in the case of natural teeth, the host response to microorganisms emerges in the foreground [20]. Clinical and animal research has shown that plaque accumulation around dental implants results in the development of an inflammatory reaction in the mucosa around the implant $[21,22]$. Bacterial contamination around the implant stimulates the inflammatory response in a similar way as in individuals with periodontitis [23].

It is known that there is a fluid in the peri-implant sulcus similar to the one in gingival sulcus. This fluid is called peri-implant crevicular fluid (PICF). Although the production mechanism and content of PICF is similar to that of gingival crevicular fluid (GCF), it may differ from GCF by volume due to structural and vasculature differences between gingival and peri-implant tissues [6]. In addition, it was concluded in previous studies that the periimplant sulcus has similarity with the gingival sulcus in the flow and microflora of the gut fluid [24]. PICF biomarkers and periimplant trough-specific microbial profile may be associated with peri-implantitis [23].

In the two-part implant systems where the implant and abutment parts are located separately from each other, the microspace formed in the implant-abutment region is the area where 


\section{Juniper Online Journal of Case Studies}

microbial accumulation is most observed [25]. Positioning of the attachment region under the soft tissue allows the micro-cavity to form a suitable environment for microorganisms [26]. It has also been reported that the vertical position of the micro cavity in the alveolar crest is related to the degree of inflammation and bone loss observed around the dental implant. The proximity of this cavity to the bone may cause bone destruction by reaching the infection to the tissues [27]. By not getting treated, the infection that starts in the surrounding soft tissues can be exacerbated and may cause bone loss by starting in the surrounding soft tissues and then progressing to bone tissue. The most important complication that dental implants face is the risk of infection when loss of bone tissue around the osseointegrated implants is detected. The infection caused by microbial accumulation observed in the surrounding tissues of dental implants has been reported as the most important cause of implant loss [28].

From a microbiological point of view, the teeth and implants have a surface structure that allows the development of bacterial additions. Bacteria accumulation on these hard surfaces is the primary cause of diseases such as tooth decay, gingivitis, periodontitis and peri-implantitis [9,29]. While irregular surfaces provide places where bacteria can be protected from cleansing forces, they increase the physical surface area and strengthen bacterial adhesion. It is known that rough surfaces are difficult to clean and the remaining bacteria form colonies again [30]. In the second and third years of a study performed by Van Steenberge et al. [31], it was reported that loss was observed in $2 \%$ of the existing implants and these losses were observed in patients with high plaque accumulation [31]. Weyant et al. [32] reported that the rate of implant loss was $4 \%$ in the patients they followed for 5 years. The most important risk factors for this loss are reported to be plaque, smoking and local factors [32].

\section{Peri-implant Tissue Microbiology}

Peri-implant diseases after successful osseointegration of intra-bone implants are caused by an imbalance between bacterial activity and host response. The response to inflammation in periimplant diseases may be confined to the mucosa around the implant as it is in the peri-implant mucositis, or it may progress and cause loss of bone tissue and lead to peri-implantitis $[9,29]$.

Periodontal and peri-implant diseases are infections caused by microorganisms. Therefore, the use of microbiological parameters has an important role in both microbial development and routine diagnosis and follow-up. It has been reported that periodontal pathogens are detectable around dental implants that begin to function in the oral environment in a short period of a month [33].

According to the researches and data obtained, it is seen that there are more similarities than differences between periodontitis and peri-implantitis [34]. In addition to the similarity of clinical findings such as edema, redness, bleeding, increased pocket depth and mobility, the pathogens involved in infections are similar. It has been reported that the pathogens observed in microbial flora in implant circumference infections are similar to those detected in periodontitis. Changes in microbial flora during the course of implantation from the healthy state to the peri-implantitis are similar to changes in microbial flora occurring during the progression of gingivitis from the healthy periodontal status in natural teeth and periodontitis from the gingivitis [35]. While at the beginning of the disease, it is observed that gram positive cocci are dominant and gram-negative species are at low rates, the number of gram-negative anaerobe and facultative anaerobic species increases as the amount of plaque increases [36]. The pathogens observed in the microbial flora in the peri-implant lesions were identified to be the red complex types (Porpyhromonas gingivalis, Treponema denticola, Tannerella forsythia) similar to those of the periodontists and orange complex species (Fusobacterium and Prevotella intermedia) defined by Socransky [37]. Agregatibacter actinomycetemcomitans (A.a) has also been reported to be isolated in peri-implantitis lesions [38,39].

After implant placement perioodontopathogens are found in healthy microflora. In a study conducted by Koka et al. [40], the existence of $P$. gingivalis, $P$. intermedia, Actinomyces naeslundii, $F$. Nucleatum and T. denticola in the plaque samples on the 14 th and 28th days after opening of the implant into the oral environment was investigated in comparison with natural teeth. According to the data obtained, these species can be determined after 14 days and within 28 days a complex subgingival microbiota has been reported to occur [40]. Although there are only a few changes in the microbial species profile around the tooth, there has been a significant increase in the amount of $F$. nucleatumss vincentii, Peptostreptococcus micros, Prevotella nigresence and $P$. Gingivalis species around the implant over time. The species such as $S$. mitis and $S$. oralis seen in early colonization on teeth were also colonized at the second week around the implants and maintained their levels for 26 weeks [41]. It has been reported that in the subgingival flora of clinically healthy implants, there is a high proportion of bacteria in the form of cocci, and that spirochetes, motile bacilli and Gram (-) anaerobic species are none or low. It has been reported that there is a high rate of spirochetes and motile bacteria in clinically deep pockets and implants with increased alveolar bone loss [42-44].

It has been proven by many investigators that the anaerobic bacteria in periodontitis microflora show a proportional increase compared to the total flora. A similar situation is valid for periimplant diseases [44]. Pathogens such as A.actinomycetecomitans, T.forsythia and P.gingivalis are responsible for the development of both periodontitis and peri-implantitis and disease progression. In addition, many pathogens such as Pintermedia, C. rectus, P.micros, F. nucleatum and E.nodatum, capnocytaphaga also play a role in these diseases. Periodontopathogenic bacteria such as porphyromonas gingivalis, treponama denticola, tannerella forsythensis and aggregatibacter actinomicetocomitans have been shown to be similar in peri-implant pockets and in periodontal pockets [45].

Peri-implantitis implants have complex microbiates including conventional periodontopathogens. Specifically, there are studies showing that classical periodontopathogens such as 


\section{Juniper Online Journal of Case Studies}

A.actinomycetemcomitans, P. gingivalis, T. forsythia, P. micra, C. rectus, F. nucleatum, P. intermedia, T. denticola and Capnocytophaga are observed in the microbiota of patients with peri-implantitis but also that these species may exist in healthy implant regions as well [46]. Other species such as Pseudomonas aeruginosa, Enterobacter species, Candida albicans and Staphylococci have also been frequently shown around implants [47]. Although these species are not frequently seen in the subgingival region, they have been also found in individuals with persistent periodontitis. In addition, high rates of S.aureus and Streptoccoccus epidermidis species are among bacteria found around the implants [48]. In a study on this subject, 40 subgingival bacterial species were examined in 22 peri-implantitis and 8 healthy implant regions, and only 4 bacterial species were directly associated with peri-implantitis. These species are P. nigrescens, P. micros, F. nucleatum ss vincentii, F. nucleatum ss nucleatum. Although there were no statistically significant differences, $P$. gingivalis, $T$. forsythia and T. denticola species were found to be high in periimplantitis implants and the prevalence of $S$. gordonii, S. mitis and $P$. intermedia species was emphasized in the healthy areas [36]. When Leonhardt et al. [49] compared microbial flora found in the vicinity of healthy implants with the one in implants where peri-implantitis observed, they reported that in the study group $60 \%$ of the implants were detected with $P$. gingivalis, $P$. intermedia, A. actinomycetemcomitans and P.nigressence with 55\% Staphylococcus spp., enteric and Candida spp. and none of these microorganisms were detected in the healthy group [49].

\section{Conclusion}

As known, the most important etiological factor that threatens peri-implant tissue health is microbial dental plaque and its content as in periodontal tissues. From this point of view, the amount and pathogenicity of the microorganisms in the microbial dental plaque accumulated around the implants is important as in natural teeth. Therefore, the examination of microbiological parameters has an important place in routine diagnosis and follow-up. In most of the studies, dental implant success was evaluated according to clinical parameters and implants in the mouth and more studies are needed in microbiological aspects.

\section{References}

1. Chattman R (1970) Implantology: history and review. Bull Plainfield Dent Soc 2(2): 15-19.

2. Wang F, Song YL, Li DH, Li CX, Wang Y, et al. (2010) Type 2 diabetes mellitus impairs bone healing of dental implants in GK rats. Diabetes Res Clin Pract 88(1): e7-e9.

3. Abu Hantash RO, Al-Omiri MK, Al-Wahadni AM (2006) Psychologica impact on implant patients' oral health-related quality of life. Clin Oral Implants Res 17(2): 116-123.

4. Apse P, Zarb GA, Schmitt A, Lewis DW (1991) The longitudinal effectiveness of osseointegrated dental implants. The Toronto Study: peri-implant mucosal response. Int J Periodontics Restorative Dent 11(2): 94-111.

5. Berglundh T, Lindhe J, Ericsson I, Marinello CP, Liljenberg B, et al (1991) The soft tissue barrier at implants and teeth. Clin Oral Implants Res 2(2): 81-90.
6. Lang NP, Berglundh T (2011) Periimplant diseases: where are we now? --Consensus of the Seventh European Workshop on Periodontology. J Clin Periodontol 38 Suppl 11: 178-181.

7. Derks J, Tomasi C (2015) Peri-implant health and disease. A systematic review of current epidemiology. J Clin Periodontol 42 Suppl 16 S158-S171.

8. Mombelli A, van Oosten MA, Schurch E, Land NP (1987) The microbiota associated with successful or failing osseointegrated titanium implants. Oral Microbiol Immunol 2(4): 145-151.

9. Zitzmann NU, Berglundh T (2008) Definition and prevalence of periimplant diseases. J Clin Periodontol 35(8 Suppl): 286-291.

10. Nassar H, Kantarci A, van Dyke TE (2007) Diabetic periodontitis: a model for activated innate immunity and impaired resolution of inflammation. Periodontol 2000 43: 233-244.

11. Eick S, Pfister W (2002) Comparison of microbial cultivation and a commercial PCR based method for detection of periodontopathogenic species in subgingival plaque samples. J Clin Periodontol 29(7): 638644.

12. Nonnenmacher C, Mutters R, de Jacoby LF (2001) Microbiological characteristics of subgingival microbiota in adult periodontitis, localized juvenile periodontitis and rapidly progressive periodontitis subjects. Clin Microbiol Infect 7(4): 213-217.

13. Socransky SS, Haffajee AD (2002) Dental biofilms: difficult therapeutic targets. Periodontol 2000 28: 12-55.

14. van Winkelhoff AJ (2003) Microbiology in diagnosis and treatment planning in periodontics. Int J Dent Hyg 1(3): 131-137.

15. Fenesy KE (1998) Periodontal disease: an overview for physicians. Mt Sinai J Med 65(5-6): 362-369.

16. Sanz M, Lau L, Herrera D, Morillo JM, Silva A (2004) Methods of detection of Actinobacillus actinomycetemcomitans, Porphyromonas gingivalis and Tannerella forsythensis in periodontal microbiology, with special emphasis on advanced molecular techniques: a review. J Clin Periodontol 31(12): 1034-1047.

17. Jervoe-Storm PM, Koltzscher M, Falk W, Dorfler A, Jepsen S (2005) Comparison of culture and real-time PCR for detection and quantification of five putative periodontopathogenic bacteria in subgingival plaque samples. J Clin Periodontol 32(7): 778-783.

18. Sakamoto M, Umeda M, Benno Y (2005) Molecular analysis of human oral microbiota. J Periodontal Res 40(3): 277-285.

19. Haffajee AD, Teles RP, Socransky SS (2006) Association of Eubacterium nodatum and Treponema denticola with human periodontitis lesions. Oral Microbiol Immunol 21(5): 269-282.

20. Romeo E, Ghisolfi M, Carmagnola D (2004) Peri-implant diseases. A systematic review of the literature. Minerva Stomatol 53(5): 215-230.

21. Schierano G, Pejrone G, Brusco P, Trombetta A, Martinasso G, et al (2008) TNF-alpha TGF-beta2 and IL-1beta levels in gingival and periimplant crevicular fluid before and after de novo plaque accumulation. J Clin Periodontol 35(6): 532-538.

22. Moon IS, Berglundh T, Abrahamsson I, Linder E, Lindhe J (1999) The barrier between the keratinized mucosa and the dental implant. An experimental study in the dog. J Clin Periodontol 26(10): 658-663.

23. Wang HL, Garaicoa-Pazmino C, Collins A, Ong HS, Chudri R, et al. (2016) Protein biomarkers and microbial profiles in peri-implantitis. Clin Oral Implants Res 27(9): 1129-1136.

24. Apse P, Ellen RP, Overall CM, Zarb GA (1989) Microbiota and crevicular fluid collagenase activity in the osseointegrated dental implant sulcus: a comparison of sites in edentulous and partially edentulous patients. J Periodontal Res 24(2): 96-105. 
25. Broggini N, McManus LM, Hermann JS, Medina R, Schenk RK, et al. (2006) Peri-implant inflammation defined by the implant-abutment interface. J Dent Res 85(5): 473-478.

26. Broggini N, McManus LM, Hermann JS, Medina RU, Oates TW, et al. (2003) Persistent acute inflammation at the implant-abutment interface. J Dent Res 82(3): 232-237.

27. Degidi M, Perrotti V, Shibli JA, Novaes AB, Piattelli A, et al. (2011) Equicrestal and subcrestal dental implants: a histologic and histomorphometric evaluation of nine retrieved human implants. J Periodontol 82(5): 708-715.

28. Van Assche N, Pittayapat P, Jacobs R, Pauwels M, Teughels W, et al. (2011) Microbiological outcome of two screw-shaped titanium implant systems placed following a split-mouth randomised protocol, at the 12th year of follow-up after loading. Eur J Oral Implantol 4(2): 103-116.

29. Lindhe J, Meyle J (2008) Peri-implant diseases: Consensus Report of the Sixth European Workshop on Periodontology. J Clin Periodontol 35(8 Suppl): 282-285.

30. Teughels W, Van Assche N, Sliepen I, Quirynen M (2006) Effect of material characteristics and/or surface topography on biofilm development. Clin Oral Implants Res 17 Suppl 2: 68-81.

31. van Steenberghe D, Klinge B, Linden U, Quirynen M, Herrmann I, et al. (1993) Periodontal indices around natural and titanium abutments: a longitudinal multicenter study. J Periodontol 64(6): 538-541.

32. Weyant RJ (1994) Characteristics associated with the loss and periimplant tissue health of endosseous dental implants. Int J Oral Maxillofac Implants 9(1): 95-102.

33. Leonhardt A, Adolfsson B, Lekholm U, Wikstrom M, Dahlen G (1993) A longitudinal microbiological study on osseointegrated titanium implants in partially edentulous patients. Clin Oral Implants Res 4(3): 113-120.

34. Heitz-Mayfield LJ, Lang NP (2010) Comparative biology of chronic and aggressive periodontitis vs. peri-implantitis. Periodontol 200053 : 167-181.

35. Porras R, Anderson GB, Caffesse R, Narendran S, Trejo PM (2002) Clinical response to 2 different therapeutic regimens to treat periimplant mucositis. J Periodontol 73(10): 1118-1125.

36. Salcetti JM, Moriarty JD, Cooper LF, Smith FW, Collins JG, et al. (1997) The clinical, microbial, and host response characteristics of the failing implant. Int J Oral Maxillofac Implants 12(1): 32-42.

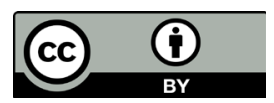

This work is licensed under Creative Commons Attribution 4.0 License DOI: 10.19080/JOJCS.2018.09.555756
37. Socransky SS, Haffajee AD, Cugini MA, Smith C, Kent RL, et al. (1998) Microbial complexes in subgingival plaque. J Clin Periodontol 25(2): 134-144.

38. Hultin M, Gustafsson A, Hallstrom H, Johansson LA, Ekfeldt A, et al. (2002) Microbiological findings and host response in patients with peri-implantitis. Clin Oral Implants Res 13(4): 349-358.

39. van Winkelhoff AJ, Wolf JW (2000) Actinobacillus actinomycetemcomitans-associated peri-implantitis in an edentulous patient. A case report. J Clin Periodontol 27(7): 531-535.

40. Koka S, Razzoog ME, Bloem TJ, Syed S (1993) Microbial colonization of dental implants in partially edentulous subjects. J Prosthet Dent 70(2): 141-144.

41. Quirynen M, Vogels R, Peeters W, van Steenberghe D, Naert I, et al. (2006) Dynamics of initial subgingival colonization of 'pristine' periimplant pockets. Clin Oral Implants Res 17(1): 25-37.

42. Rams TE, Roberts TW, Tatum H, Keyes PH (1984) The subgingival microbial flora associated with human dental implants. J Prosthet Dent 51(4): 529-534.

43. Persson LG, Ericsson I, Berglundh T, Lindhe J (2001) Osseintegration following treatment of peri-implantitis and replacement of implant components. An experimental study in the dog. J Clin Periodontol 28(3): 258-263.

44. Mombelli A, Buser D, Lang NP (1988) Colonization of osseointegrated titanium implants in edentulous patients. Early results. Oral Microbiol Immunol 3(3): 113-120.

45. Sato J, Gomi K, Makino T, Kawasaki F, Yashima A, et al. (2011) The evaluation of bacterial flora in progress of peri-implant disease. Aust Dent J 56(2): 201-206.

46. Shibli JA, Melo L, Ferrari DS, Figueiredo LC, Faveri M, et al. (2008) Composition of supra- and subgingival biofilm of subjects with healthy and diseased implants. Clin Oral Implants Res 19(10): 975-982.

47. Slots J, Rams TE (1991) New views on periodontal microbiota in special patient categories. J Clin Periodontol 18(6): 411-420.

48. Rams TE, Feik D, Slots J (1990) Staphylococci in human periodontal diseases. Oral Microbiol Immunol 5(1): 29-32.

49. Leonhardt A, Renvert S, Dahlen G (1999) Microbial findings at failing implants. Clin Oral Implants Res 10(5):339-345.

\section{Your next submission with Juniper Publishers} will reach you the below assets

- Quality Editorial service

- Swift Peer Review

- Reprints availability

- E-prints Service

- Manuscript Podcast for convenient understanding

- Global attainment for your research

- Manuscript accessibility in different formats

(Pdf, E-pub, Full Text, Audio)

- Unceasing customer service

Track the below URL for one-step submission https://juniperpublishers.com/online-submission.php 